\title{
Intention toward the continuation of female genital mutilation in Bale Zone, Ethiopia
}

\author{
This article was published in the following Dove Press journal: \\ International Journal of Women's Health \\ 9 January 2015 \\ Number of times this article has been viewed
}

\section{Daniel Bogale' \\ Desalegn Markos ${ }^{2}$ \\ Muhammedawel Kaso' \\ 'Department of Public Health, ${ }^{2}$ Department of Nursing, College of Medicine and Health Sciences, Madawalabu University, Bale Goba, Ethiopia}

Background: Female genital mutilation (FGM) is a harmful traditional practice that is deeply rooted in Africa. It is associated with health complications and human rights violations. Research on intention for the continuation of FGM and the social determinants underpinning this practice are scarce. Therefore, this study intended to assess the intention of women toward the continuation of FGM among Bale Zone reproductive-age women.

Methods: A community-based cross-sectional study design supplemented by qualitative methods was conducted in 2014. A total of 634 reproductive-age women were involved in the quantitative part of the study. The respondents were drawn from five randomly selected districts of Bale Zone. The total sample was allocated proportionally to each district based on the number of reproductive-age women it has. Purposive sampling method was used for qualitative study. Then, data were collected using a pretested and structured questionnaire. The collected data were analyzed by Statistical Package for Social Sciences for Windows version 16.0. Multiple logistic regressions were carried out to examine the existence of a relationship between intentions for the continuation of FGM and selected determinant factors.

Results: This study revealed that $26.7 \%$ of the respondents had intention for the continuation of FGM. Religion, safeguarding virginity, tradition, and social values were the major reasons for the perpetuation of this practice. Circumcised respondents and those who were not able to read and write were $\sim 3$ (adjusted odds ratio $=2.89,95 \%$ confidence interval $=[1.33,6.20]$ ) and 7.58 (adjusted odds ratio $=7.58,95 \%$ confidence interval $=[3.47,16.54]$ ) times more likely intending the continuation of FGM than uncircumcised and those who attended secondary-level education and above, respectively.

Conclusion: The study shows that the intention toward the persistence of the practice is high in Bale Zone. Rural residents, those who were not able to read and write, and circumcised respondents were more likely to continue the practice.

Keywords: females' genital mutilation, intention, continuation, Bale Zone

\section{Background}

Female genital mutilation (FGM) consists of all procedures that involve partial or total removal of the external female genitalia or other injury to the female genital organs whether for cultural or other nontherapeutic reasons. ${ }^{1}$ As defined by the World Health Organization, ${ }^{1,2}$ there are three types of FGM. Type I consists of excision of the clitoral prepuce, and it is known in Muslim countries as the Sunnah circumcision. Type II involves excision of the prepuce, the removal of the glans clitoris, or the entire clitoris with varying degrees of the adjacent parts of the labia minora. This is often referred to simply as excision. Type III is termed infibulation and is also referred to as Pharaonic circumcision. It involves removal of the whole clitoris, the whole of the labia minora, and the medial parts of the labia majora. It is a form of sex inequality that remains deeply entrenched in the social and economic structures of the countries
Correspondence: Daniel Bogale Department of Public Health, College of Medicine and Health Sciences, Madawalabu University, PO Box 302, Bale Goba, Ethiopia

Tel +2519 I28I 8II7

Email bogaleodo@gmail.com 
and communities where it is practiced. ${ }^{3}$ The practice is common for many ethnic groups in the country, especially for Oromo people with different types of procedure and levels of performance.

It is estimated that around 140 million girls and women worldwide have undergone FGM, and that at least two million girls annually are at risk of undergoing some form of the procedure. ${ }^{4}$ It is common in several countries, predominantly in Africa. ${ }^{1}$ The prevalence of FGM in the countries of northeastern Africa (Egypt, Eritrea, Ethiopia, and northern Sudan) ranges from $80 \%$ to $97 \%$, while that of eastern Africa (Kenya and Tanzania) ranges from $18 \%$ to $38 \% .^{5}$

Ethiopia has taken steps toward the abolition of this practice and created a supportive policy environment in which various local and international organizations can work toward the elimination of the practice. In spite of this, the practice remains widespread. According to data from the 2005 Ethiopian Demographic and Health Survey, three out of every four women had undergone FGM. ${ }^{6}$ Thirty-eight percent of women with a daughter reported having at least one of their daughters circumcised and that about a third of all women support the continuation of the practice. FGM is practiced in all regions in Ethiopia, but the magnitude varies considerably from region to region ranging from less than $30 \%$ in Gambella and Tigray to over $90 \%$ in Afar, Dire Dawa, and Somali. ${ }^{7}$ According to the study conducted in East Hararge, Kersa district, only $23.7 \%$ of the respondents attempted to stop this practice. ${ }^{8}$ It is deeply embedded in society, and its elimination requires a clear understanding of the cultural perceptions and beliefs it feeds on. ${ }^{4}$

Key drivers perpetuating FGM vary across the world. It is a deeply rooted social and cultural requirement for girls before marriage. Higher social recognition, fulfilling a religious requirement, and reducing female sexual desire ${ }^{9}$ are the major perceived reasons to perpetuate this practice. Failure to conform to FGM leads to social exclusion, ostracism, disapproval, or even violence in addition to having an effect on a girl's marriageability. Conformity, on the other hand, meets with social approval, brings respect and admiration, and maintains social standing for a girl and her family in the community. ${ }^{3}$ Supporters of the practice rely on religion and tradition to defend their belief. ${ }^{10}$ The practice of FGM derives from a complex belief set, in which cultural tradition takes precedence within a frame of sexual, moral, and religious reasons that are sustained through community mechanisms. ${ }^{11}$ It is believed to reduce sexual lust, which was seen as easily aroused and difficult to control thus likely to lead the uncut woman to sexual promiscuity, ${ }^{3,11}$ but above all, it is to ensure a woman's virginity before marriage and fidelity thereafter. ${ }^{3}$ Together with FGM, premarital chastity and marital fidelity were seen to function as proof of morality, granting the woman social respect. ${ }^{11}$ Regardless of differences in the religion they follow or ethnic group they belong to, all the aforementioned reasons are expected in Bale Zone in particular, and in Ethiopia in general.

FGM carries serious health consequences both for the girl or woman who undergoes the procedure and for her offspring. ${ }^{2}$ Most women who have undergone FGM live in countries with limited infrastructure for health care or for health research, ${ }^{1}$ which makes it difficult to get immediate care if complications occur. Immediate and long-term health consequences have been identified with the practice of FGM. Immediate complications include severe pain, shock, hemorrhage, urine retention, ulceration of the genital region, and injury to adjacent tissue. ${ }^{12}$ Long-term health effects include psychological and psychosexual trauma, infertility, susceptibility to bacterial vaginosis and genital herpes, and obstetric complications including perinatal death. . $2,6,13,14^{2}$

FGM obviously violates the fundamental ethical principles of bodily integrity, autonomy, and self-determination without the full informed consent of the victim. Therefore, it violates the same social norms and social integrity. ${ }^{9}$

Despite the banning of the practice within some countries, the eradication of FGM is still a problem, as the practice merely gets hidden from the eyes of the public and continues quietly. ${ }^{15}$ Understanding the forces underpinning FGM is a necessary first step to prevent the continuation of a practice that is associated with health complications and human rights violations. While there are some data on the prevalence of FGM, there is paucity of information on intention of the community toward the continuation of FGM. To the knowledge of the authors, there is no study conducted on the same topic in Bale Zone. Therefore, this study was intended to assess the intention of women toward the continuation of FGM among Bale Zone reproductive-age women.

\section{Methods}

The study was conducted in Bale Zone from April 18, 2014, to May 20, 2014. It is one of the 18 rural zones of Oromia regional state located in the southeast of Ethiopia. It is the second largest zone in the region with an area of $67,329.6 \mathrm{~km}^{2}$ that extends from $5^{\circ} 22^{\prime}$ to $8^{\circ} 08^{\prime} \mathrm{N}$ latitudes and $38^{\circ} 41^{\prime}$ to $40^{\circ} 44^{\prime} \mathrm{E}$ longitudes and having $14.93 \%$ high-land, $21.54 \%$ mid-land, and $63.55 \%$ low-land distribution. Robe is the zonal capital. ${ }^{16}$ Eighty percent of the zone is composed of farmers and agro pastoralists. There are ten farmers, 
eight agro pastoralists, and two town administrative districts in the zone. The composition of rural and urban population is $87.5 \%$ and $12.5 \%$, respectively. According to the 2007 census, Bale Zone had a total population of 1,418,864, of whom 697,185 were females. ${ }^{17}$ A community-based, quantitative, cross-sectional study design supplemented by qualitative study was employed.

\section{Population}

Bale Zone women of childbearing-age were the source population for this study. For quantitative study, the study population included all childbearing-age women found in five randomly selected districts, namely, childbearing-age women of Agarfa district, Dinsho district, Madawalabu district, Berbere district, and Robe town. The study subjects were randomly selected reproductive-age women from aforementioned districts. For qualitative study, the same districts were used to select women for focus group discussion (FGD) and in-depth interviews for the triangulation of quantitative findings. A total of four FGDs and eight in-depth interviews were made with purposively selected women.

\section{Sample size and sampling procedure}

A single population sample size determination formula was employed to calculate the sample size. The proportion $(p)$ of intention for the continuation of FGM in the study area was assumed to be $50 \%$. Ninety-five percent confidence level with $5 \%$ margin of error was considered. Multiplying by 1.5 for design effect and adding 10\% for nonresponse rate, the final total sample size was 634 childbearing-age women.

The first step of the sampling procedure for quantitative study involved stratifying 20 districts into three groups based on their livelihood. The three strata were agrarian, pastoralist, and town administrative districts. The assumption behind this stratification was as follows: there is difference in accessibility of information and composition of society in different districts. Then, one district from town administrative stratum, two districts from agrarian, and two districts from pastoralist (a total of five districts) were selected randomly from the list of each stratum. Finally, the total sample size was proportionally allocated to five districts after the number of reproductive-age women was determined. Three kebeles (the smallest administrative unit) were selected from each district through simple random sampling. After the number of women in that kebele was determined, sample size allocated for each district was allocated again to each kebele. Finally, women in that kebele were selected by simple random sampling method. For qualitative study, purposive sampling method was employed to select women both for indepth interview and FGD. The authors felt there were issues a woman might not discuss in a group freely because this practice is highly connected with cultural and social values. The problem a woman encountered might be better explained in an in-depth interview. FGDs having on average eight participants were arranged on purposively selected kebeles. FGDs were arranged both on rural and urban settings.

\section{Data collection tool}

A structured and standardized tool ${ }^{18}$ that included all the relevant variables to meet the objectives of this study was used after it was translated into local language. The tool was translated to both Amharic and Afan Oromo by a person who has very good knowledge of English, Afan Oromo, and Amharic languages. Another individual with similar ability translated the Amharic and Afan Oromo version back to English to check for its original meaning.

\section{Data collection and quality control Quantitative data collection}

Eight diploma nurses who were fluent in speaking Amharic and Afan Oromo were involved in the data collection process. All data collectors and supervisors were trained for 2 days on the data collection technique based on the guide that was developed by the principal investigator. The data collection tool was pretested on a $5 \%$ similar population in one of the districts that was not included in the actual study. Findings and experiences from the pretest were utilized in modifying the tool. The principal investigator and the supervisors strictly followed the overall activities on a daily basis to ensure the completeness of questionnaire and to give further clarification and support for data collectors.

\section{Qualitative data collection}

Homogeneous purposive sampling method was employed to select discussants for FGD and in-depth interviews. The groups for FGD were made homogeneous in terms of social class and age. This helped the participants to talk freely about whatever they knew. The study setting was chosen such that the privacy of the participants could be maintained, the location was comfortable, noisy areas were avoided, and the location was easily accessible.

\section{Operational definition}

Measuring an intention using a single variable may not be practical especially for an issue tied with social and cultural norms. For this study, if a woman answered "yes" for at least 
two of the following questions, she was considered as having an intention for the continuation of this practice: Have you planned to circumcise your daughter? Do you support the continuation of FGM? To stop FGM is going against the norm? FGM is a religious requirement?.

\section{Data processing, analysis, and presentation}

The data were checked for completeness and consistencies, then cleaned, coded, and entered onto a computer using Statistical Package for Social Sciences Windows version 16.0. Descriptive statistics were computed to determine the level of intention for the continuation of FGM. Additionally, binary and multiple logistic regression analyses were carried out to examine the existence of a relationship between intention and the selected independent variables. Statistical significance was declared at $P<0.05$. For the qualitative part, data were transcribed into English by the principal investigator by replaying the recorded interview. Different ideas in the text were merged in their thematic areas, and a thematic framework analysis was employed manually. Then, the result was presented in narration by triangulating the quantitative findings.

\section{Ethical considerations}

The proposal was approved by Ethical Review Committee of Madawalabu University. In addition to this, letters of permission were obtained from Bale Zone Administrative and Health office and from each of the woredas administrative and health office. Furthermore, verbal consent was obtained from the study subjects after explaining the study objectives and procedures and their rights to refuse not to participate in the study any time they wanted, were assured. For this very purpose, a one page consent letter was attached to the cover page of each questionnaire stating the general objective of the study and issues of confidentiality.

\section{Results}

\section{Sociodemographic characteristics of the study participants}

Of the total 634 reproductive-age women who were planned for the study, 619 were successfully interviewed yielding a response rate of $97.6 \%$. The mean age of the study participants was 30 years (standard deviation \pm 9.2 years). More than $16 \%$ of the respondents $(101[16.3 \%])$ were in the age group of 15-20 years. Muslim was found as a predominant religion, which accounted for 366 (59.1\%) participants, followed by orthodox Christian (36.5\%).
More than one third of the participants (233 [37.6\%]) reported that they were educated up to primary school, which is almost equal to those who were not able to read and write (229 [37\%]). One hundred twenty-nine (22.5\%) husbands of the study subjects were unable to read and write, while $114(37.3 \%)$ of them had secondary-level education and above (Table 1).

A majority (540 [87.2\%]) of the respondents were Oromo ethnic group and the vast majority (574 [92.7\%]) of them were married. Only six (1\%) women were single. A large number (448 [72.4\%]) of study subjects were housewives, and the monthly income of 159 (34\%) participants was less than 500 Ethiopian Birr. The occupation of 150 (43.6\%) husbands of the respondents was farming (Table 1).

\section{Intention toward the continuation of FGM}

Four hundred forty-eight (72.4\%) study participants had daughters, of whom 399 had at least one uncircumcised daughter. Of the total study subjects, 165 (26.7\%) had intention for the continuation of FGM. This point estimate value fell within the range of 23-30. Of those who had uncircumcised daughters, $120(19.4 \%)$ had plans to have their daughters circumcised. One hundred sixty-nine $(27.3 \%)$ respondents reported that they support FGM to be continued on their daughters or on any other girls in the future. Of the total study participants, 269 (43.5\%) reported that their religion requires female circumcision. One hundred twenty-eight $(20.7 \%)$ respondents reported that to stop FGM is going against the norm. One hundred two $(16.5 \%)$ respondents perceived that male group supports female circumcision (Table 2).

There were different reasons given by the qualitative study participants for FGM to be perpetuated in their community:

\section{Religion as a reason}

If a girl undergoes circumcision, she is said to be "Halaalfamte" to mean she is pure so she can follow Islamic religion. Otherwise, whatever she is strong in accomplishing all religious requirements, she is not accepted by "Allah". So what is beyond religion for a person? [37-years-old grade 4 agrarian woman]

Everyone who says I am Muslim should undergo circumcision. It is one of the obligations for a Muslim. Now the government tries to end female's genital mutilation but I think noone will be out of his religion. On this type of issue better to deal with religious leaders; we are the followers. [31-year-old pastoral woman] 
Table I Sociodemographic characteristics of the respondents; Bale Zone, Oromia region, southeast Ethiopia, May 2014

\begin{tabular}{|c|c|c|}
\hline & Frequency & Percent \\
\hline \multicolumn{3}{|l|}{ Age of respondent, years } \\
\hline $15-20$ & 101 & 16.3 \\
\hline $21-25$ & 163 & 26.3 \\
\hline $26-30$ & 128 & 20.7 \\
\hline $31-35$ & 57 & 9.2 \\
\hline $36-49$ & 170 & 27.5 \\
\hline Total & 619 & 100.0 \\
\hline \multicolumn{3}{|l|}{ Marital status } \\
\hline Single & 6 & 1 \\
\hline Married & 574 & 92.7 \\
\hline Divorced & 25 & 4 \\
\hline Widowed & 14 & 2.3 \\
\hline \multicolumn{3}{|l|}{ Religion } \\
\hline Muslim & 366 & 59.1 \\
\hline Orthodox Christian & 226 & 36.5 \\
\hline Protestant & 27 & 4.4 \\
\hline \multicolumn{3}{|l|}{ Ethnicity } \\
\hline Oromo & 540 & 87.2 \\
\hline Amhara & 79 & 12.8 \\
\hline \multicolumn{3}{|l|}{ Respondents' educational status } \\
\hline Unable to read and write & 229 & 37 \\
\hline Read and write & 9 & 1.5 \\
\hline Primary-level education & 233 & 37.6 \\
\hline Secondary-level education and above & 148 & 23.9 \\
\hline \multicolumn{3}{|l|}{ Husband's education } \\
\hline Unable to read and write & 129 & 22.5 \\
\hline Read and write & 25 & 4.4 \\
\hline Primary-level education & 206 & 35.9 \\
\hline Secondary-level education and above & 214 & 37.3 \\
\hline \multicolumn{3}{|l|}{ Respondents' occupation } \\
\hline Housewife & 448 & 72.4 \\
\hline Government employee & 33 & 5.3 \\
\hline Self-employed & 10 & 1.6 \\
\hline Farmer & 24 & 3.9 \\
\hline Merchant & 84 & 13.6 \\
\hline Other & 20 & 3.2 \\
\hline \multicolumn{3}{|l|}{ Husband's occupation } \\
\hline Farmer & 250 & 43.6 \\
\hline Government employee & 118 & 20.6 \\
\hline Self-employed & 44 & 7.7 \\
\hline Merchant & 115 & 20.0 \\
\hline Other & 47 & 8.2 \\
\hline \multicolumn{3}{|l|}{ Residence } \\
\hline Rural & 129 & 20.8 \\
\hline Urban & 490 & 79.2 \\
\hline \multicolumn{3}{|l|}{ Income } \\
\hline$<500$ & 159 & 34 \\
\hline $500-1,000$ & $|5|$ & 32.3 \\
\hline $\mathrm{I}, 00 \mathrm{I}-2,000$ & 114 & 24.4 \\
\hline$>2,000$ & 44 & 9.4 \\
\hline
\end{tabular}

According to our "Sheria" it is an obligation for a mother to circumcise her daughter. Leave a girl who has a mother, the one who her mother died should undergoes the procedure by her relatives or by neighboring mother. [48-year-old pastoral woman]
Table 2 Intention for the continuation of FGM/C of the respondents; Bale Zone, Oromia region, southeast Ethiopia, May 2014

\begin{tabular}{|c|c|c|}
\hline Variables & Frequency & Percent \\
\hline \multicolumn{3}{|c|}{ Plan for daughter(s) circumcision } \\
\hline Yes & 120 & 19.4 \\
\hline No & 279 & 45.1 \\
\hline All circumcised & 49 & 7.9 \\
\hline Has no daughter & 171 & 27.6 \\
\hline \multicolumn{3}{|c|}{ Support the continuation of FGM/C } \\
\hline Yes & 169 & 27.3 \\
\hline No & 450 & 72.7 \\
\hline \multicolumn{3}{|c|}{ Circumcised woman does not practice premarital sex } \\
\hline Yes & 112 & 18.1 \\
\hline No & 401 & 64.8 \\
\hline Has no idea & 106 & 17.1 \\
\hline \multicolumn{3}{|c|}{ Uncircumcised woman is promiscuous } \\
\hline Yes & 139 & 22.5 \\
\hline No & 371 & 59.9 \\
\hline Has no idea & 109 & 17.6 \\
\hline \multicolumn{3}{|c|}{ Uncircumcised woman cannot manage her marriage } \\
\hline Yes & 97 & 15.7 \\
\hline No & 459 & 74.2 \\
\hline Has no idea & 63 & 10.2 \\
\hline \multicolumn{3}{|c|}{ FGM is a religious requirement } \\
\hline Yes & 269 & 43.5 \\
\hline No & 302 & 48.8 \\
\hline Does not know & 48 & 7.8 \\
\hline \multicolumn{3}{|l|}{ Males support FGM } \\
\hline Yes & 102 & 16.5 \\
\hline No & 385 & 62.2 \\
\hline Does not know & 132 & 21.3 \\
\hline \multicolumn{3}{|c|}{ To stop FGM is going against the norm } \\
\hline Yes & 128 & 20.7 \\
\hline No & 462 & 74.6 \\
\hline Has no idea & 29 & 4.7 \\
\hline \multicolumn{3}{|c|}{ FGM/C exposes females for HIVIAIDS } \\
\hline True & 439 & 70.9 \\
\hline False & 93 & 15.0 \\
\hline Does not know & 87 & 14.1 \\
\hline
\end{tabular}

Abbreviation: $\mathrm{FGM} / \mathrm{C}$, female genital mutilation/cutting.

A girl should be circumcised because she is expected to pray when she is 15 year old "solat". If she is not circumcised, her solat will not be accepted by Allah and not considered further Muslim. [37-year-old pastoral woman who did not attend school]

Religious leaders are our exemplary and our teachers. However, till now I heard nothing from religious leaders on this issue whether it is harmful or not. "Allah" puts them to teach us everything which is good for us. They were thought as to stop this practice if it is against the religion. [30-year-old agrarian woman who attended grade 8]

\section{Safeguarding virginity as a reason}

Uncircumcised girl does not maintain her virginity until she gets married because she has very high sexual desire 
than the circumcised one. Once she lost her virginity, as a chance if she gets married, she will turn to her family immediately after her marriage. [37-year-old agrarian woman who attend grade 2]

I have three daughters of which two of them were circumcised before two years. The youngest one is now eight years old. All the time I observe their behavior closely. The two older daughters are staying calm for everything but I afraid the youngest one. She is trying to test everything. Anyhow, I had a plan to circumcise her soon. [39-year-old agrarian woman who did not attend school]

We are moving with cattle throughout the year so that we have no time to keep our daughters. The only solution to control girl's sexual desire is putting her under circumcision. Especially if her genital is sewn after the procedure, there is no fear for her family. [32-year-old pastoral woman]

\section{Culture/custom as a reason}

Even if FGM has immediate and long-term problems, it is our obligation to pass through this procedure because it is what our mothers did it before. Now a day, the previous intensive procedure is not there. Just it is for "Sunnah" (cutting only on the tip of clitoris) to obey Sheria. [34-year-old agrarian woman who attended grade 5]

We did not tell our problem to anyone why you concerned on this issue? It is up to us to tolerate this practice since we are female. It is not started now rather it is our ancestors culture. [48-year-old pastoral woman]

I think our mothers transfer this practice to us because it has some importance. Likewise, we have to maintain it and transfer for the coming generation. Even if the government tried to stop this practice, all mothers keep practicing it in a hidden way. [49-year-old agrarian woman]

Here I have question; circumcision is common both for male and female; no one is talking about male circumcision but why ours is so strange? Do you think all our mothers were wrongdoers? I don't think so. [44-year-old woman who did not attend formal education]

There is no woman who is unaware of the health consequences of FGM. However, opposing this practice is considered as being against the culture and religion. I know FGM is not written in the Holy Qur'an but we accepted it as it is religious requirement with no evidence. Anyhow, we are not beyond religious leaders. [25-year-old grade 10 completed, agrarian woman]

\section{Economic survival/marriage of girls as a reason}

When a girl approaches her 15 years of birthday, her father expects five to ten camels from her marriage. This is possible if and only if she is circumcised. No one wants to appoint uncircumcised girl for marriage. [39-year-old pastoral woman who did not attend school]

Not only her family who feels shame her relatives also feel shame so they push her family to put a girl under circumcision. If one asks men, they all prefer to marry a circumcised girl. [45-year-old agrarian woman who attended grade 4]

Even if a father does not present on the ceremony, he is the one who plays a role in facilitating things beforehand. Unless he will be ignored by his friends and he cannot walk in the community. [36-year-old agrarian woman who did not attend school]

Living in a given community is possible if and only if you can accept its norms. Every woman knows the problem related with FGM but it is deep rooted social culture which may be difficult to stifle it easily. I also passed through this procedure when I was 9 years old. I could not say anything because it was my obligation. [28-year-old agrarian woman attending grade 7]

\section{Factors associated with intention for the continuation of FGM}

The odds of intention for the continuation of FGM was about six times higher among rural residents than their urban counterparts (adjusted odds ratio $[A O R]=5.73,95 \%$ confidence interval $[\mathrm{CI}]=[3.44,9.55])$. Respondents' educational level is another variable that was associated with the intention for the continuation of FGM. Those study subjects who were unable to read and write were about eight times more likely intending to continue FGM (AOR $=7.58,95 \% \mathrm{CI}=[3.47$, 16.54]) than those who attend secondary-level education and above. In addition to these two variables, circumcised respondents were nearly three times more likely to intend the continuation of FGM than uncircumcised respondents (AOR $=2.89,95 \% \mathrm{CI}=[1.33,6.20])$. Age is only significant at binary logistic regression level (Table 3 ).

\section{Discussion}

Despite global and local attempts to end FGM, the practice persists in some parts of the world. ${ }^{19}$ The current study proved $26.7 \%$ of the respondents were intending to perpetuate FGM either on their daughters or on other girls in the future. This 
Table 3 Factors associated with the intention for the continuation of FGM among the respondents; Bale Zone, Oromia region, southeast Ethiopia, May 2014

\begin{tabular}{|c|c|c|c|c|}
\hline \multirow[t]{2}{*}{ Variable } & \multicolumn{2}{|c|}{$\begin{array}{l}\text { Intention for FGM } \\
\text { continuation }\end{array}$} & \multirow[t]{2}{*}{$\begin{array}{l}\text { COR ( } 95 \% \text { confidence } \\
\text { interval) }\end{array}$} & \multirow[t]{2}{*}{$\begin{array}{l}\text { Adjusted odds ratio } \\
\text { ( } 95 \% \text { confidence interval) }\end{array}$} \\
\hline & Yes, N (\%) & No, N (\%) & & \\
\hline \multicolumn{5}{|l|}{ Residence } \\
\hline Rural & 85 (65.9) & $44(34.1)$ & $9.90(6.40,|5.3|)^{* *}$ & $5.73(3.44,9.55)^{* *}$ \\
\hline Urban & $80(16.3)$ & $410(83.7)$ & 1 & $\mathrm{I}$ \\
\hline \multicolumn{5}{|l|}{ Age, years } \\
\hline $15-20$ & $26(25.7)$ & $75(74.3)$ & $\mathrm{I}$ & I \\
\hline $2 I-25$ & $32(19.6)$ & |3| (80.4) & $0.7 \mathrm{I}(0.39, \mathrm{I} .27)$ & $0.83(0.42, \mathrm{I} .66)$ \\
\hline $26-30$ & $36(28.1)$ & 92 (7I.9) & I.I $3(0.63,2.03)$ & $0.92(0.44,1.92)$ \\
\hline $31-35$ & $18(31.6)$ & $39(68.4)$ & I.33 $(0.65,2.72)$ & $0.78(0.32,1.93)$ \\
\hline $36-49$ & $53(3 \mathrm{I} .2)$ & II 7 (68.8) & I.3I $(0.75,2.27)$ & $0.92(0.44, \mathrm{I} .88)$ \\
\hline \multicolumn{5}{|l|}{ Religion } \\
\hline Muslim & 143 (39.1) & $223(60.9)$ & $2.82(1.05,7.62)^{*}$ & $\mathrm{I} .46(0.45,4.7 \mathrm{I})$ \\
\hline Orthodox & $17(7.5)$ & $209(92.5)$ & $0.36(0.12,1.06)$ & $0.42(0.12,1.48)$ \\
\hline Protestant & $5(18.5)$ & $22(81.5)$ & I & $\mathrm{I}$ \\
\hline Education & & & & 1 \\
\hline Unable to read and write & II 5 (48.3) & $123(5 \mathrm{I} .7)$ & $12.90(6.47,25.73)^{* *}$ & $7.58(3.47,16.54)^{* *}$ \\
\hline Primary-level education & $40(17.2)$ & 193 (82.8) & $2.86(I .38,5.9 \mid)^{* *}$ & $1.97(0.88,4.40)$ \\
\hline Secondary-level education & $10(6.8)$ & 138 (93.2) & I & I \\
\hline \multicolumn{5}{|l|}{ Circumcised } \\
\hline Yes & $156(32.1)$ & 330 (67.9) & $6.51(3.22,13.15)^{* *}$ & $2.89(1.33,6.20)^{*}$ \\
\hline No & $9(6.8)$ & 124 (93.2) & $\mathrm{I}$ & $\mathrm{I}$ \\
\hline
\end{tabular}

Notes: *Significant at $P<0.05$, **significant at $P<0.01$.

Abbreviation: FGM, female genital mutilation; COR, crude odds ration.

finding is lower than the result from Egypt, in which $32 \%$ of women intend to have their daughters circumcised; ${ }^{5}$ in Iraq $34.2 \%$ of the women agreed the practice of FGM should continue ${ }^{20}$ and in Mauritania $64 \%$ respondents favored the continuation of the practice. ${ }^{8}$ These discrepancies might have resulted from cultural and social variation between these study areas. In addition to this, there might be difference in operational definition for intention between these studies. This finding was also compared with the study conducted in Nigeria, in which $21 \%$ of the respondents reported that they were going to have FGM performed on their daughters. ${ }^{21}$ The previous study was a facility-based study, while the current study employed a community-based approach, by which this slight difference might be justified.

In the current study, of those who had uncircumcised daughters, $19.4 \%$ of respondents had planned to put their daughters under the procedure, which is lower than the proportion reported by the study conducted in Hargeisa, Somalia, which shows $85 \%$ of the respondents had planned to have their daughters circumcised. ${ }^{22}$ This great discrepancy might have resulted from cultural and social differences of the two study settings.

In this study about $71 \%$ of the study subjects perceived that FGM exposes a woman for HIV. The study from Hargeisa district, Somali, revealed that $88.8 \%$ of the respondents were aware of the possibility of HIV transmission. ${ }^{22}$ Our study covers the wider geographic areas consisting of communities with multiple social and cultural aspects. In addition to this, this study considered only women as study subjects. Furthermore, there might be variation in accessing sources of information among these study subjects.

The present study shows that $16.5 \%$ of the study subjects reported that they thought males support the continuation of this practice. This finding is lower than the finding from Mauritania, and $37 \%$ of women perceived males wanted to continue the practice. ${ }^{8}$ There could be social and cultural differences between the two studies. In addition to this, the finding of the previous study was extracted from 2001 demographic and health survey documents, which is somewhat longer ago than the recent study.

The woman herself willing to undergo circumcision was a predictor of intending the perpetuation of FGM on their daughters or on other girls. Women who were themselves willing to undergo circumcision were 2.89 times more likely intending to put their daughters under the procedure than their counterpart uncircumcised women. Respondents who could not read and write were 7.58 times more likely intending to perpetuate FGM on their daughters than those who attended secondary-level education and above. An important observation is that in communities where genital 
mutilation is accepted, it is practiced even by women who are educated up to the primary level. There is, however, a tendency for women with high school education and above to either be indifferent or disapprove of this practice, suggesting that as more women acquire higher education, the practice of FGM in the study area will get reduced. This trend could be further encouraged by special attention to this type of harmful traditional practice in primary level of education. The other variable independently predicting the likelihood of intending to circumcise daughters was place of residence. Those residing in rural areas were 5.73 times more likely intending to perform FGM on their daughters. This result was in agreement with the finding from Jimma zone, southwest Ethiopia, and Egypt. ${ }^{6,7,9}$

While the large sample size as well as the mixed study design approach constitutes a major strength for this study, it also has some limitations. Considering that FGM is a very sensitive and stigmatizing social issue in the study area, this leaves room to question the truthfulness of a respondent when questioned by an unknown interviewer. In addition to this, the likelihood for women to give culturally acceptable answers to the interviewer constitutes a real concern. Interpretation of the current finding with respect to other results needs care because there might be differences in data collection tools, time, and culture among the study subjects in different settings. This also imposed challenges to compare the findings with similar studies.

\section{Conclusion}

This study shows that women's intention toward the continuation of FGM is high in Bale Zone. Religion, safeguarding virginity, economic survival of girls, culture, custom, and marriageability of girls were the main reasons justified by the study participants for the perpetuation of this practice. As education is an important variable in exposing young adults to the health and psychosocial consequences of FGM, encouraging the youth beyond primary education is also likely to make a significant contribution to put an end to the practice.

\section{Acknowledgments}

Funding for this study was made possible through grants offered by Madawalabu University. The authors are grateful to the respondents who offered their time to participate in this study. The authors especially thank the research assistants who participated in data collection and also thank the zonal and woreda health offices for their cooperation.

\section{Disclosure}

The authors report no conflicts of interest in this work.

\section{References}

1. World Health Organization. Female genital mutilation and obstetric outcome: WHO collaborative prospective study in six African countries. Lancet. 2006;367:1835-1841.

2. Bishai D, Bonnenfant YT, Darwish M, et al; FGM Cost Study Group of World Health Organization. Estimating the obstetric costs of female genital mutilation in six African countries. Bull World Health Organ. 2010;88:281-288.

3. UNICEF Innocenti Research Centre. The Dynamics of Social Change Towards the Abandonment of Female Genital Mutilation/Cutting in Five African Countries. Florence: United Nations Children's Fund (UNICEF), UNICEF Innocenti Research Centre; 2010.

4. Isman E, Warsame A, Johansson A, Fried S, Berggren V. Midwives' experiences in providing care and counselling to women with female genital mutilation (FGM) related problems. Obstetrics Gynecol International. 2013;2013:9.

5. Afifi M. Women's empowerment and the intention to continue the practice of female genital cutting in Egypt. Arch Iran Med. 2009; 12(2):154-160.

6. Central Statistical Agency [Ethiopia] and ORC Macro. Ethiopia Demographic and Health Survey 2005. Addis Ababa, Ethiopia and Calverton, Maryland, USA: Central Statistical Agency and ORC Macro; 2006. Available from: http://dhsprogram.com/pubs/pdf/FR179/ FR179[23June2011].pdf. Accessed December 12, 2014.

7. Mariam AG, Hailemariam A, Belachew T, Michael KW, Lindstrom D. Support for the continuation of female genital mutilation among adolescents in Jimma zone, southwest Ethiopia. Ethiop J Health Sci. 2009;19:2.

8. Yirga WS, Kassa NA, Welday M, Gebremichael MW, Aro AR. Female genital mutilation: prevalence, perceptions and effect on women's health in Kersa district of Ethiopia. Int J Womens Health. 2012;4:45-54.

9. Ouldzeidoune N, Keating J, Bertrand J, Rice J. A Description of female genital mutilation and force-feeding practices in Mauritania: implications for the protection of child rights and health. PLoS One. 2013;8(4):e60594.

10. Elsayed DEM, Elamin RM, Sulaiman SM. Female genital mutilation and ethical issues. Sudanese J Public Health. 2011;6(2):63-67.

11. Berg RC, Dedison EA. Tradition in transition: factors perpetuating and hindering the continuance of female genital mutilation/cutting (FGM/C) summarized in a systematic review. Health Care Women Int. $2013 ; 34: 837-859$

12. Wadesango N, Rembe S, Chabaya O. Violation of women's rights by Harmful traditional practices. Anthropologist. 2011;13(2):121-129.

13. Morison L, Scherf C, Ekpo G, et al. The long-term reproductive health consequences of female genital cutting in rural Gambia: a communitybased survey. Tropical Med Int Health. 2001;6(8):643-653.

14. Kaplan A, Forbes M, Bonhoure I, et al. Female genital mutilation/cutting in the Gambia: long-term health consequences and complications during delivery and for the newborn. Int $J$ Womens Health. 2013;5: 323-331.

15. Hoffmann N. Female genital mutilation in Egypt. Global J Med Public Health. 2013;2:3.

16. Nigatu D. Women's Autonomy Regarding Their Own and Children's Health Care Utilization and Associated Factors in Goba Woreda $[\mathrm{MPH}$ thesis]. Bale Zone: south east Ethiopia; 2011. (Unpublished).

17. FDRE Population Census commission and UNFPA. Summary and Statistical Report of the 2007 Ethiopian Population and Housing Census Results. Ethiopia: Addis Ababa; 2008.

18. Yoder PS, Abderrahim N, Zhuzhuni A. Female Genital Cutting in the Demographic and Health Surveys: A Critical and Comparative Analysis. Calverton, MD, USA: ORC Macro; 2004. 
19. Turillazzi E, Fineschi V. Female genital mutilation: the ethical impact of the new Italian law. J Med Ethics. 2007;33:98-101.

20. Pashaei T, Rahimi A, Ardalan A, Felah A, Majlessi F. Related factors of female genital mutilation (FGM) in Ravansar (Iran). $J$ Womens Health Care. 2012;1(2):108.
21. Mandara MU. Female genital mutilation in Nigeria. International $J$ Gynecol Obstetrics. 2004;84:291-298.

22. Gele AA, Bø BP, Sundby J. Have we made progress in Somalia after 30 years of interventions? Attitudes toward female circumcision among people in the Hargeisa district. BMC Res Notes. 2013;6:122.
International Journal of Women's Health

\section{Publish your work in this journal}

The International Journal of Women's Health is an international, peerreviewed open-access journal publishing original research, reports, editorials, reviews and commentaries on all aspects of women's healthcare including gynecology, obstetrics, and breast cancer. The manuscript management system is completely online and includes

\section{Dovepress}

a very quick and fair peer-review system, which is all easy to use. Visit http://www.dovepress.com/testimonials.php to read real quotes from published authors.

\footnotetext{
Submit your manuscript here: http://www.dovepress.com/international-journal-of-womens-health-journal
} 